\title{
CALCIUM PHOSPHATE CEMENT MODIFIED WITH SILICON NITRIDE/TRICALCIUM PHOSPHATE MICROGRANULES
}

\author{
Lubomir Medvecky, Radoslava Stulajterova, Maria Giretova, Tibor Sopcak, Maria \\ Faberova, Miroslav Hnatko, Tatana Fenclova
}

\begin{abstract}
Tetracalcium phosphate/monetite biocement was modified with 10 and $30 \mathrm{wt}$ \% addition of highly porous silicon nitride/ $\alpha$-tricalcium phosphate ( $\alpha T C P)$ microgranules with various content of $\alpha T C P$. A composite cement powder mixture was prepared using mechanical homogenization of basic components. The accelerated release of dexamethasone from composite cement was revealed, which indicates their possible utilization for controlled drug release. The wet compressive strength of cements $(<17 \mathrm{MPa})$ was significantly reduced (more than $30 \%)$ in comparison with the unmodified cement and both compressive strength and setting time were influenced by the content of aTCP in microgranules. The addition of microgranules caused a $20 \%$ decrease in final cement density. Microgranules with a higher fraction of $\alpha T C P$ showed good in vitro SBF bioactivity with precipitation of hydroxyapatite particles. Microstructure analysis of fractured cements demonstrated excellent interconnection between microgranules and cement calcium phosphate matrix, but also showed lower mechanical strength of microgranule cores.
\end{abstract}

Keywords: calcium phosphate, biocement, microstructure, dexamethasone, drug release

\section{INTRODUCTION}

The moldable calcium phosphate cements (CPC) [1-3] avoid the problem of sintered hydroxyapatite implants that require the surgeon to fit the surgical site around the implant or to carve the implant to the desired shape. CPC has been used in a number of orthopedic and dental procedures [4,5] but unfortunately, the relatively low strength and susceptibility to brittle fracture of CPC have severely limited its use to non-load-bearing applications [6,7]. Tetracalcium phosphate cements represent one of the widely used cement types due to their excellent osteoconductivity, biocompatibility, and bone-bonding ability. It has been shown that the hardening process was significantly affected by the particle size distribution of TTCP and monetite cement components, $\mathrm{Ca} / \mathrm{P}$ ratio as well as addition of organic additives (e.g. carboxylic acids, alginates) or various powder inorganic fillers (e.g. inert oxides $-\mathrm{SiO}_{2}, \mathrm{ZrO}_{2}$, or silicon nitride whiskers) [8-12]. Improved fracture toughness, compressive and flexural strengths were found in $\mathrm{HA} / \mathrm{Al}_{2} \mathrm{O}_{3}$ ceramic composites, but alumina had a negative effect on HA stability in air sintered ceramics due to the formation of secondary calcium aluminates $[13,14]$. A similar situation was registered for $\mathrm{ZrO}_{2} / \mathrm{Al}_{2} \mathrm{O}_{3} / \mathrm{HA}$ composites where the decomposition to $\beta \mathrm{TCP}$ was illustrated after sintering [15].

\footnotetext{
Lubomir Medvecky, Radoslava Stulajterova, Maria Giretova, Tibor Sopcak, Maria Faberova: Institute of Materials Research of SAS, Watsonova 47, 04001 Kosice, Slovakia

Miroslav Hnatko: Institute of Inorganic Chemistry of SAS, Dubravska cesta, Bratislava, Slovakia

Tatana Fenclova: Faculty of Metallurgy and Materials Engineering, Technical University of Ostrava, Ostrava, Czech Republic
} 
Silicon nitride as non-oxide ceramics offers several advantages in comparison to routinely used oxide bioceramics, mainly significantly higher fracture toughness and wear resistance resulting in high reliability of implants [16-18]. A high bioinertness, flexural strength, and low cytotoxicity of $\mathrm{Si}_{3} \mathrm{~N}_{4}$ /bioglass or $\mathrm{MgO}$ ceramic composites were verified before [19]. It was demonstrated improved wettability and good wear resistance of $\mathrm{Si}_{3} \mathrm{~N}_{4}$ ceramic composites [20]. Several industrial $\mathrm{Si}_{3} \mathrm{~N}_{4}$ ceramic types showed no cytotoxicity and a strong influence of surface texture on in vitro cytotoxicity [21]. Cancellous structured $\mathrm{Si}_{3} \mathrm{~N}_{4}$ ceramic showed good bone ingrowth at depths of penetration greater than $3 \mathrm{~mm}$ after 12 weeks since implantation [22]. It was observed the formation of hydroxyapatite layer on $\mathrm{Si}_{3} \mathrm{~N}_{4}$ ceramic using soaking in simulated body fluid (SBF) which verified in vitro SBF bioactivity of ceramics [23]. The flexural strength of the SiC/nanosilica whisker-CPC BisGMA-based resin composites was 3 times higher than the strength achieved in previous studies of conventional bioactive composites containing hydroxyapatite particles [24]. Similar strengthening of $\mathrm{CPC} /$ resin composite cement was observed applying $\mathrm{Si}_{3} \mathrm{~N}_{4}$ whiskers irregardless of their silanization [25]. The 5 wt. \% addition of SrHA whiskers significantly improved the mechanical properties of calcium phosphate cement [26]. On the other hand, the bending strength of CPC was influenced by magnesium wire reinforcing where the optimal content of $\mathrm{Mg}$ wires was about 12 vol. \% [27].

In this paper, the mechanical and physicochemical properties, as well as microstructure of calcium phosphate cement modified with the addition of silicon nitride $/ \alpha$ tricalcium phosphate microgranules (Simicro), were evaluated. Besides the effect of microgranules on control of drug release (dexamethasone) from CPC was demonstrated. Dexamethasone is a representative of glucocorticoids with an anti-inflammation effect and strong influence on gene regulation and mesenchymal cell differentiation $[28,29]$. The microstructure analysis was focused especially on the mutual interconnection between cement matrix and microgranules. Composite cements were prepared by mechanical mixing of tetracalcium phosphate/monetite cement mixture (TTCPMH) with Simicro.

\section{MATERIALS AND METHODS}

\section{Preparation of cement mixtures}

The TTCPMH powder mixture was synthesized by the in situ reaction between TTCP and a diluted solution of orthophosphoric acid (86\%, analytical grade, Merck) in solution with water/ethanol (1/4) for $30 \mathrm{~min}$ in the planetary ball mill with both agate vessel and balls ( 3 balls, diameter $1 \mathrm{~cm}$ ). The final $\mathrm{Ca} / \mathrm{P}$ mole ratio in TTCPMH was equal to 1.67. Tetracalcium phosphate $\left(\mathrm{Ca}_{4}\left(\mathrm{PO}_{4}\right)_{2} \mathrm{O}\right.$, TTCP) was prepared by the solid-state synthesis from an equimolar mixture composed of calcium carbonate $\left(\mathrm{CaCO}_{3}\right.$, analytical grade, Sigma-Aldrich, Austria) and dicalcium phosphate anhydrous (DCPA) $\left(\mathrm{CaHPO}_{4}\right.$ (Ph.Eur.), Fluka, Germany) at $1450^{\circ} \mathrm{C}$ for 5 hours. The product was milled in a planetary ball mill (Fritsch, $730 \mathrm{rpm}, \mathrm{ZrO}_{2}$ balls, and vessel) for 2 hours and the phase purity was analyzed using X-ray powder diffraction analysis (XRD, Philips X Pert Pro).

The starting powder mixtures for Simicro were prepared by wet homogenization of $\mathrm{Si}_{3} \mathrm{~N}_{4}$ (UBE-SN-E10, Ube Ind. Japan) and $\alpha \mathrm{TCP}-\mathrm{Ca}_{3}\left(\mathrm{PO}_{4}\right)_{2}$ (Lachema, p.a., Czech Republic) with isopropyl alcohol in an attritor for 4 hours. The mixture was dried at $80{ }^{\circ} \mathrm{C}$ for 24 hours. The volume ratios of $\mathrm{Si}_{3} \mathrm{~N}_{4} / \alpha \mathrm{TCP}$ were 3:7 - Simicro1, 1:1 - Simicro2, and 7:3 - Simicro3. Microgranules were prepared by freezing of suspensions during stirring on a magnetic stirrer for 24 hours with $\mathrm{Si}_{3} \mathrm{~N}_{4}$ balls $(120 \mathrm{~g})$. Green microgranules were lyophilized for $48 \mathrm{~h}$ and dried at $70^{\circ} \mathrm{C}$ for $12 \mathrm{~h}$. Microgranules were sintered at $1100{ }^{\circ} \mathrm{C}$ in the air for $1 \mathrm{~h}$. Heating and cooling rates were 5 and $10^{\circ} \mathrm{C} / \mathrm{min}$, respectively. Three porous 
ceramic Simicro fractions with particle size between 25-71 (fine), 71-125 (middle), and 125-300 $\mu \mathrm{m}$ (coarse) were obtained by sieving.

Composite cement powder mixtures (CPC 1-3) were prepared by homogenization of TTCPMH and Simicro in Ultra Turrax Tube (IKA) disintegrator in ethanol for $5 \mathrm{~min}$ at $4000 \mathrm{rpm}$. After homogenization, powders were dried at $105^{\circ} \mathrm{C} / 1 \mathrm{~h}$. The contents of Simicro in CPC were 10 and 30 wt. \%.

\section{Mechanical testing, analysis of ion release during setting}

The cement pastes were prepared by mixing cement powder mixed with hardening liquid $\left(2 \% \mathrm{NaH}_{2} \mathrm{PO}_{4}\right.$ solution, powder/liquid $\left.=2: 1\right)$ and molded into pellets $(D \times H: 6 \times 12$ $\mathrm{mm}$ ) by packing in stainless cylindrical form. The samples were hardened in simulated body fluid (SBF) solution at $\mathrm{pH}=7.4$ and $37^{\circ} \mathrm{C}$ for 7 days after setting in $100 \%$ humidity at $37^{\circ} \mathrm{C}$ for 10 minutes. The dry and wet compressive strength (mean of 5 samples) was measured on a universal testing machine (LR5K Plus, Lloyd Instruments Ltd.) at a crosshead speed of $1 \mathrm{~mm} / \mathrm{min}$.

The $\mathrm{pH}$ changes and the concentration of calcium and phosphate ions after immersion of Simicro to $\mathrm{NaCl}$ solution were measured for various soaking times $(2,4,24$, 48, and 120 hours). The $450 \mathrm{mg}$ Simicro was added to $45 \mathrm{~mL}$ of $\mathrm{NaCl}$ solution at $37^{\circ} \mathrm{C}$ after 10 min setting in 100\% humidity and slowly mixed in a mini-rotator (BioRS24, Biosan) at speed of $2 \mathrm{rpm}$. The $\mathrm{pH}$ solution was measured using a $\mathrm{pH}$-meter (WTW, Inolab 720) with the SenTixMic combined electrode. The total concentrations of released calcium and phosphate ions in SBF solutions were analyzed using ICP (Horiba Activa). The true density and porosity of Simicro were measured by helium pycnometer (AccuPyc II 1340).

\section{Dexamethasone release from cements}

The release of dexamethasone (dex) from cements was analyzed using $400 \mathrm{mg}$ cement samples of the cylindrical form (6 mm in diameter) after setting with $2 \% \mathrm{NaH}_{2} \mathrm{PO}_{4}$ in $100 \%$ humidity at $37^{\circ} \mathrm{C}$ for 24 hours. Powder TTCPMH mixture (1g) was mixed with 1 $\mathrm{mL}$ of dex solution $(1 \mathrm{mg} \mathrm{dex} / \mathrm{mL}$ of ethanol) in Ultra Turrax Tube (IKA) disintegrator at $4000 \mathrm{rpm}$. In the case of composite cements, Simicro 2 microgranules were filled with an ethanolic solution of dex: $500 \mathrm{mg}$ Simicro2 mixed with $1 \mathrm{~mL}$ dex solution $(0.5 \mathrm{mg}$ dexamethasone). Mixed TTCPMHdex and Simicro2 filled with dexamethasone (Simicro2dex) were dried in a vacuum to constant mass (Illshin lyophilizer). Dried Simicro2dex were mixed with TTCPMH using dry homogenization in a mini-rotator (BioRS24, Biosan) at speed of $2 \mathrm{rpm}$ for 2 hours. This homogenization allows the preservation of dex in Simicro2 microgranules as well as to avoid their crushing or disintegration. The final CPC2dex cement contained 30 wt. \% of Simicro2dex.

\section{Phase analysis of cements}

The phase analysis of cements was carried out by X-ray diffraction analysis (Philips X'PertPro, using $\mathrm{Cu} \mathrm{K} \alpha$ radiation) and FTIR spectroscopy (Shimadzu, IRAffinity1, $400 \mathrm{mg} \mathrm{KBr}+1 \mathrm{mg}$ sample). The microstructure of cements was characterized by a field emission scanning electron microscopy (JEOL FE SEM JSM-7000F). The setting time of cement pastes was evaluated by the Vicat method (according to ISO standard 1566).

\section{Cytotoxicity of cement extracts, cell proliferation testing and analysis ALP activity}

The CPC samples (pellets, $10 \mathrm{~mm}$ in diameter, $0.5 \mathrm{~mm}$ in height) after hardening in $100 \%$ humidity at $37{ }^{\circ} \mathrm{C}$ for 24 hours in an incubator and sterilizing both sides of samples under UV irradiation in the laminar box (each side for 30 minutes) were inserted to 
a sterile $50 \mathrm{ml}$ polypropylene centrifuge tubes with cultivation medium EMEM, 10\% FBS and $1 \%$ ATB-ATM in the ratio of $0,2 \mathrm{~g}$ cement powder per $\mathrm{mL}$ of medium (in accordance with ISO 10993-12:2012). The cytotoxicity of 24 hour extracts from cements immersed in the medium was tested according to ISO 10993-5:2009. The medium (EMEM + 10\% FBS, $1 \%$ antibiotic solution) in wells with a semi-confluent monolayer of MC3T3E1 cells cultured at $37^{\circ} \mathrm{C}, 95 \%$ humidity, and $5 \% \mathrm{CO}_{2}$ in an incubator for $24 \mathrm{~h}$ was replaced with $100 \mu \mathrm{L}$ of $100 \%$ extract. Extract cytotoxicity was evaluated triplicate and cells in wells with extract-free complete culture medium were considered as a negative control. After 24 $\mathrm{h}$ cultivation, the extracts were replaced with fresh culture medium and the in vitro cytotoxicity was analyzed by the MTS proliferation test assay (Cell titer 96 aqueous one solution cell proliferation assay, Promega, USA). The absorbance of produced formazan after $4 \mathrm{~h}$ of cultivation was determined by a UV-VIS spectrophotometer (Shimadzu).

Pre-osteoblastic MC3T3E1 cells (ECAAC, Salisbury, UK) were released from culture flasks by enzymatic digestion and resuspended in a culture medium. The cell suspension was adjusted at a density of $5.0 \times 10^{4}$ cells $/ \mathrm{ml}$. $400 \mu 1$ of the complete culture medium ( $\alpha$-modification Minimum essential medium Eagle, 10\% FBS with osteogenic supplements L - ascorbic acid $50 \mu \mathrm{g} / \mathrm{ml}, 50 \mathrm{nM}$ Dexamethasone, $10 \mathrm{mM} \beta$ glycerophosphate and $1 \%$ penicillin, streptomycin, amphotericin (Sigma-Aldrich)) was added into each of the 48-well (untreated) polystyrene plates (pureGrade, Brand) with sterile cement pellets. The medium was exchanged for $400 \mu \mathrm{l}$ of the cell suspension containing $2.0 \times 10^{4} \mathrm{MC} 3 \mathrm{~T} 3 \mathrm{E} 1$ preosteoblastic cells after 1 hour soaking. All experiments were performed four-fold on each sample. As negative controls were used wells with cells free of samples and cultured at the same conditions as samples in the cellGrade culture plate (Brand). The complete culture medium was exchanged every two days. The cytotoxicity of samples was evaluated by a commercially purchased MTS proliferation test (the Cell titer 96 aqueous one solution cell proliferation assay, Promega, USA) according to the manufacturer's instructions. The absorbance of formazan was determined at $490 \mathrm{~nm}$ by a UV VIS spectrophotometer (UV-1800, Shimadzu).

The ALP activity lysates of osteoblasts was determined after lysis in a solution containing $0.1 \%$ Triton $\mathrm{X}-100,1 \mathrm{mM} \mathrm{MgCl}_{2}$ a $20 \mathrm{mM}$ Tris. The cell lysates were transferred into $1.5 \mathrm{ml}$ microcentrifuge polypropylene tubes, frozen at $-20{ }^{\circ} \mathrm{C}$, and centrifuged at 10.000 RPM for 10 minutes after thawing. The $100 \mu \mathrm{L}$ of cell supernatant was added to $100 \mu \mathrm{l}$ of p-nitrophenyl phosphate in diethanolamine buffer $(0.5 \mathrm{mM} \mathrm{MgCl}$, $\mathrm{pH} 9.8$ ) and incubated at $37^{\circ} \mathrm{C}$. The reaction was stopped after 60 minutes with $50 \mu \mathrm{L}$ of 3 $\mathrm{M} \mathrm{NaOH}$. The amount of p-nitrophenol produced by the ALP enzyme catalysis of the pnitrophenyl phosphate substrate was determined from the calibration curve of p-nitrophenol at $405 \mathrm{~nm}$ using the UV VIS spectrophotometer. The ALP activities were expressed in micromoles of the p-nitrophenol produced per 1 minute per microgram of proteins. The content of proteins in lysates was evaluated by Bradford's method with Coomasie blue G250 as a complexing agent [30]. The statistical evaluation of results $(n=4)$ was performed using ANOVA analysis (Statmost) at level $\alpha=0.05$.

The morphology of the MC3T3E1 cells after cultivation on cement samples was visualized with fluorescent live/dead staining (fluorescein diacetate/propidium iodide) by fluorescent microscopy (Leica DM IL LED). 


\section{EXPERIMENTAL RESULTS \\ Microstructure of microgranules}

The morphology and microstructure of Simicro are shown in Fig. 1. In Simicro 3 with the highest amount of $\mathrm{Si}_{3} \mathrm{~N}_{4}$ phase (Fig. 1c), irregularly shaped particle agglomerates with a size of about $30-50 \mu \mathrm{m}$ represented the majority portion of particles whereas bigger more spherical 80-100 $\mu \mathrm{m}$ agglomerates (microgranules) were in much lower number. Notably, a large fraction of finer particles (or agglomerates) visible in the image was the result of grinding of microgranules during bonding of samples on adhesive tape which demonstrates a low mechanical strength of Simicro 3. On the other hand, a limited amount of crushed microgranules was identified in Simicro 1 (Fig. 1a) and 2 (Fig. 1b) where microgranules with $100-120 \mu \mathrm{m}$ in diameter represented the majority fraction in powder materials.

\section{Phase and FTIR analysis, SBF in vitro bioactivity of microgranules}

Two phases, $\mathrm{Si}_{3} \mathrm{~N}_{4}$ (PDF4 01-073-1210) and $\alpha \mathrm{TCP}$ (PDF4 00-029-0359) were identified in Simicro by the XRD phase analysis (Fig. 2a). In FTIR spectra, peaks from vibrations of $\alpha \mathrm{Si}_{3} \mathrm{~N}_{4}$ at 1091, 1033, 958, 937,906, 892, 871, 853, 686, 678, 600, 564, 510, 497 and $461 \mathrm{~cm}^{-1}$ were identified [31]. In the case of $\alpha$ TCP, it was difficult to distinguished bands characteristic for vibrations of phosphate groups in $\alpha \mathrm{TCP}$ because of overlap with spectrum of $\alpha \mathrm{Si}_{3} \mathrm{~N}_{4}$ and no sharp peaks are specific for this compound in IR spectra. Despite two distinct strong bands arise from anti-symmetric $\mathrm{P}-\mathrm{O}$ bending triply degenerated, $v_{4}$, between 560-613 $\mathrm{cm}^{-1}$ and anti-symmetric $\mathrm{P}-\mathrm{O}$ stretching triply degenerated, $v_{3}$, symmetric $\mathrm{P}-\mathrm{O}$ stretching, $v_{1}$ between $980-1040 \mathrm{~cm}^{-1}$ can be found in spectra (Fig. 2b) [32,33]. The decrease in intensity of bands at around $1040 \mathrm{~cm}^{-1}$ and between $570-600 \mathrm{~cm}^{-1}$ with lowering the content of $\alpha \mathrm{TCP}$ in microgranules (differences between spectrum Simicro 1 and 3 in (Fig. 2b) was revealed. Note that the rise in sintering temperature to $1200^{\circ} \mathrm{C}$ caused enhanced oxidation of $\mathrm{Si}_{3} \mathrm{~N}_{4}$ with the strengthening of microgranules. As resulted from the comparison of FTIR spectra in Fig. 2c or XRD patterns (Fig. 2a), no changes in phase composition of Simicro2 and 3 were observed after soaking of microgranules in SBF at $37{ }^{\circ} \mathrm{C}$ for 10 days, however, the lower sensitivity of the XRD method to the possible amorphous form of apatite phase so as an insufficient amount of this phase could be the reason for this conclusion. In XRD patterns of Simicro1 after soaking, broad peaks around $2 \theta \sim 32^{\circ}$ and $26^{\circ}$ were identified, which correspond with the lines from reflections of nanocrystalline HAP. 

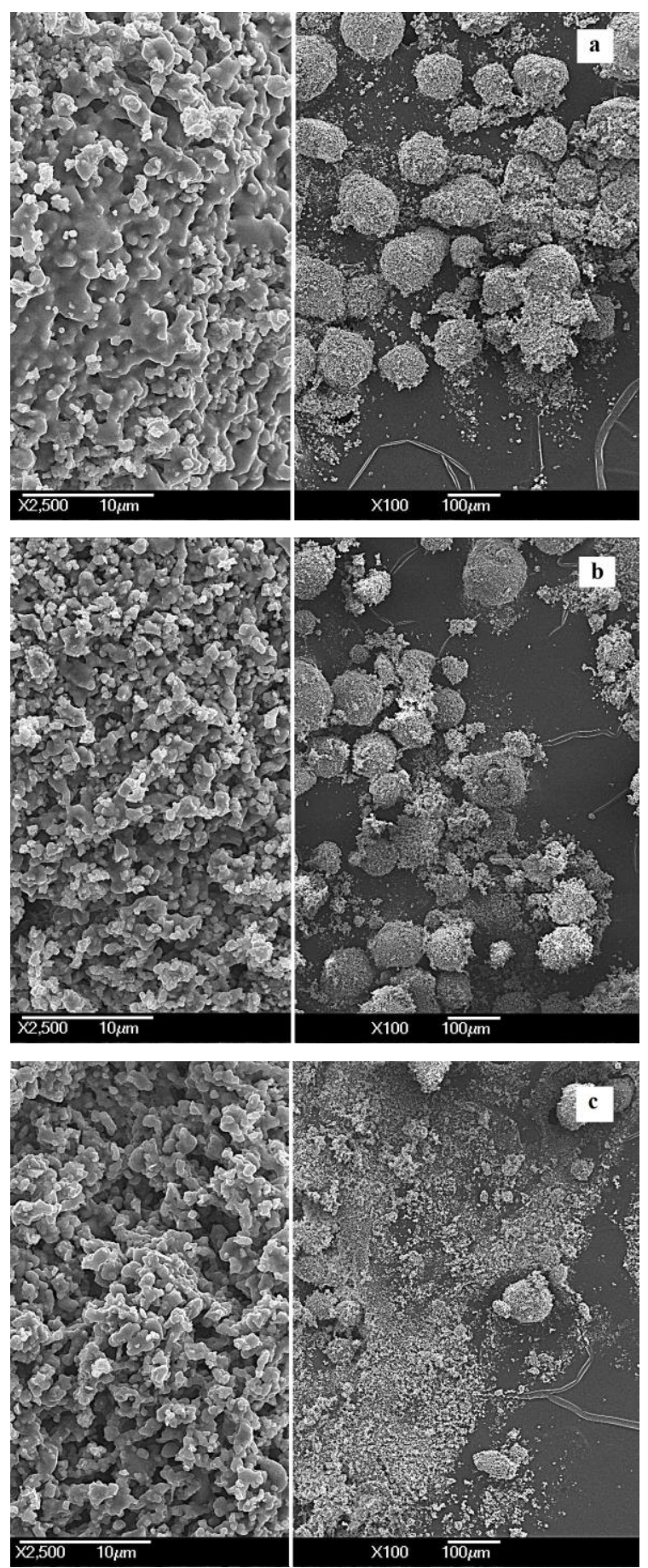

Fig. 1. Morphology and microstructure of Simicro: a) Simcro1; b) Simicro2; c) Simicro3. 


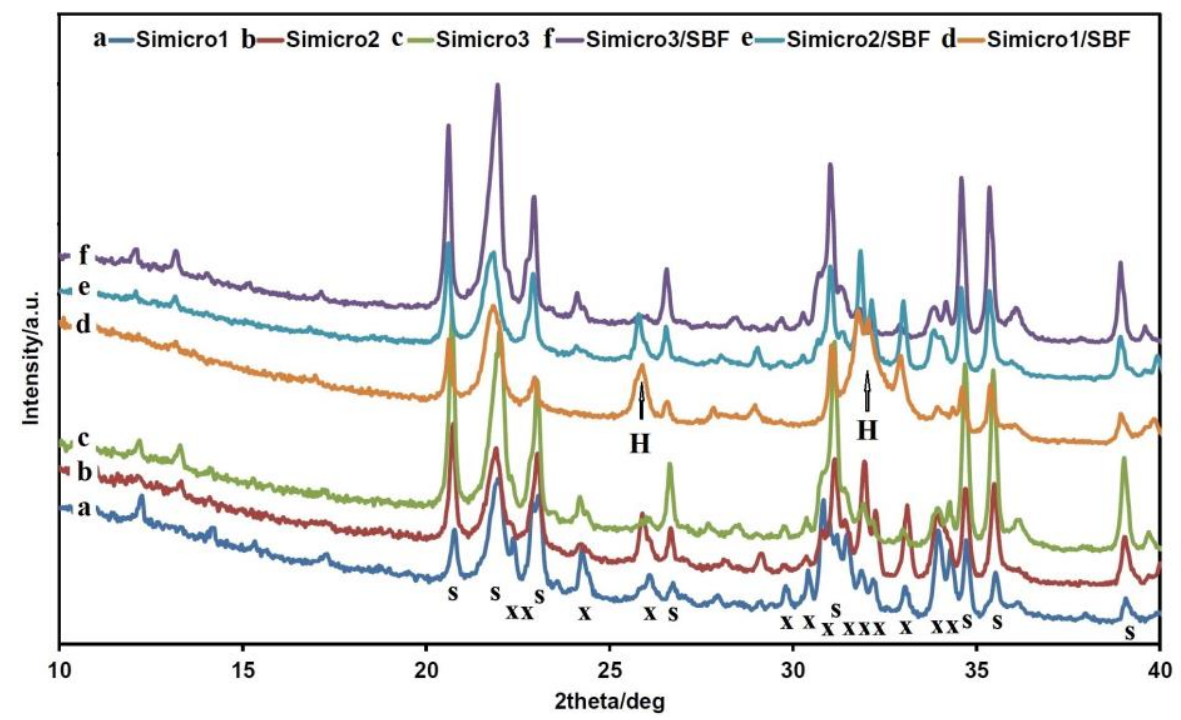

a)

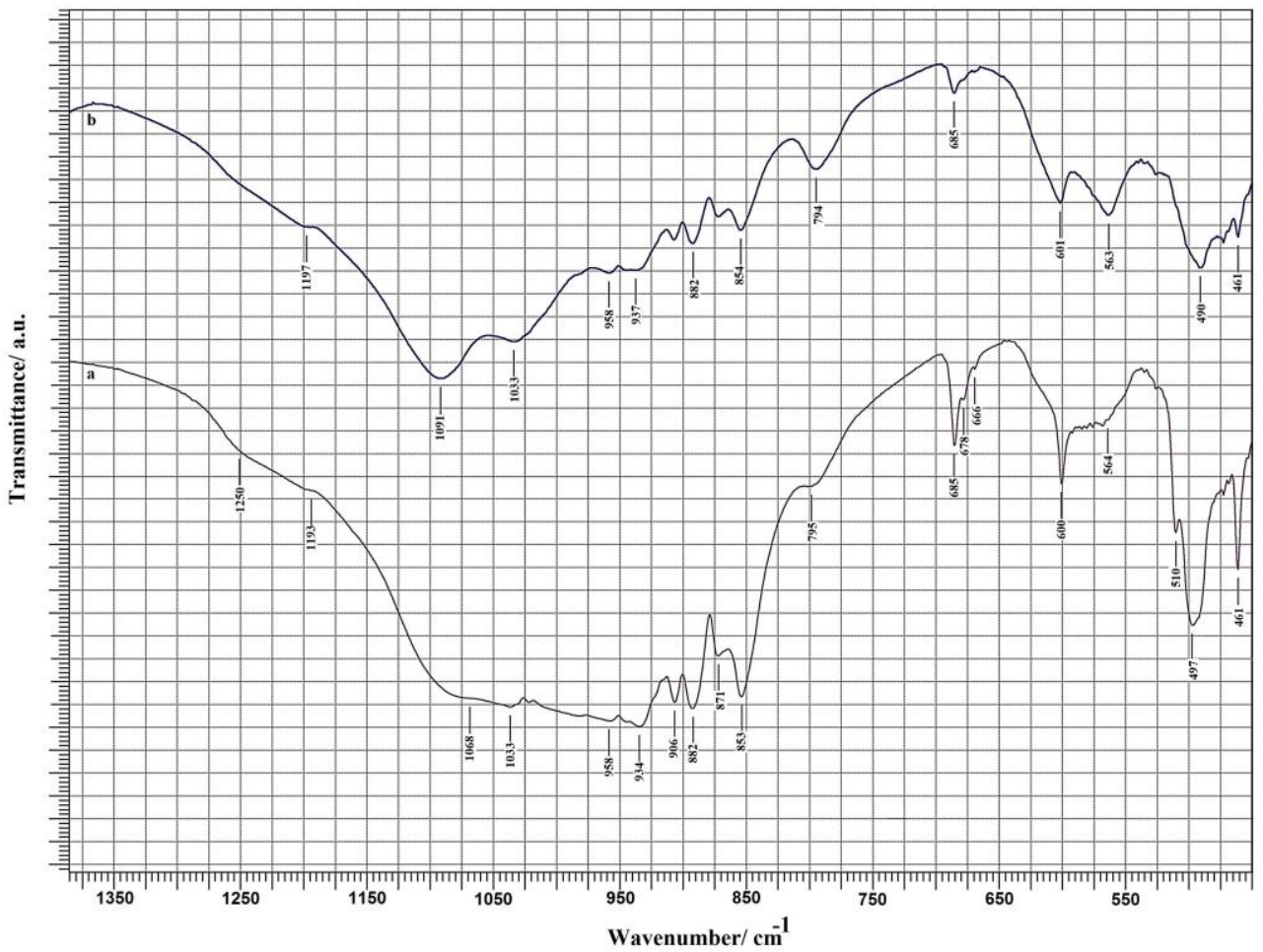

b) 


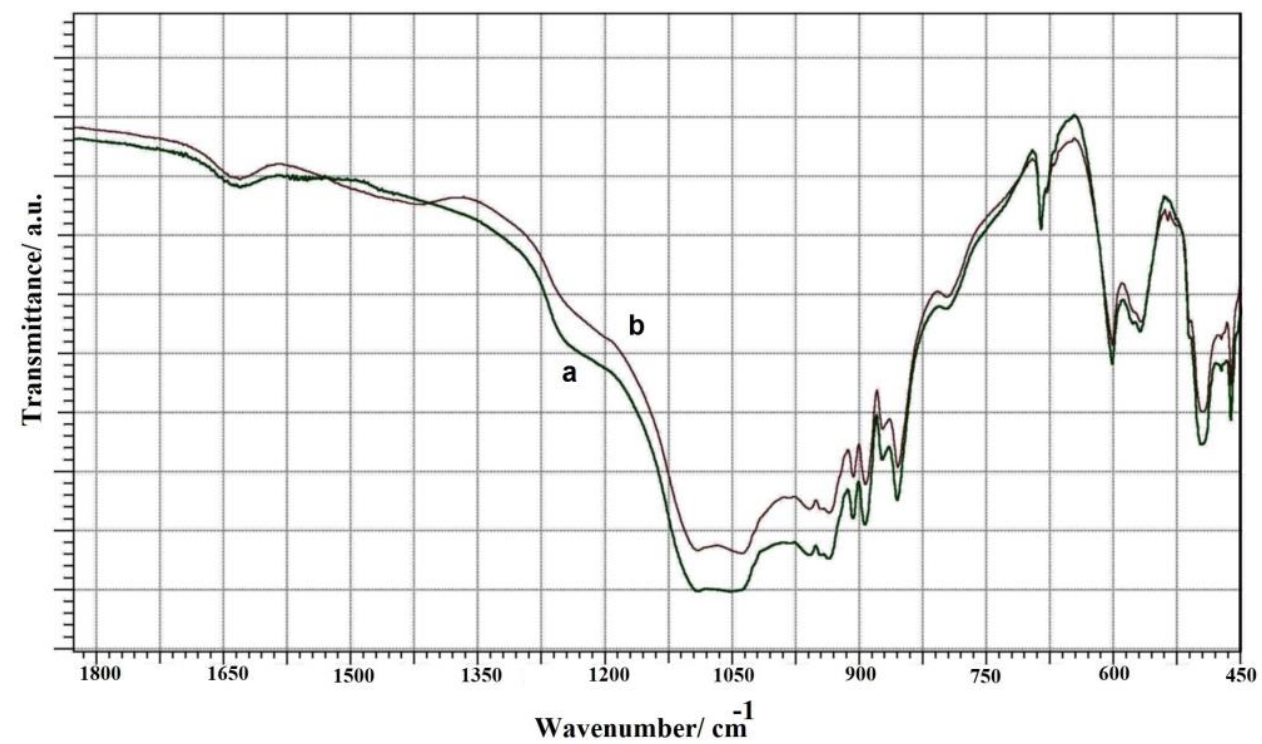

c)

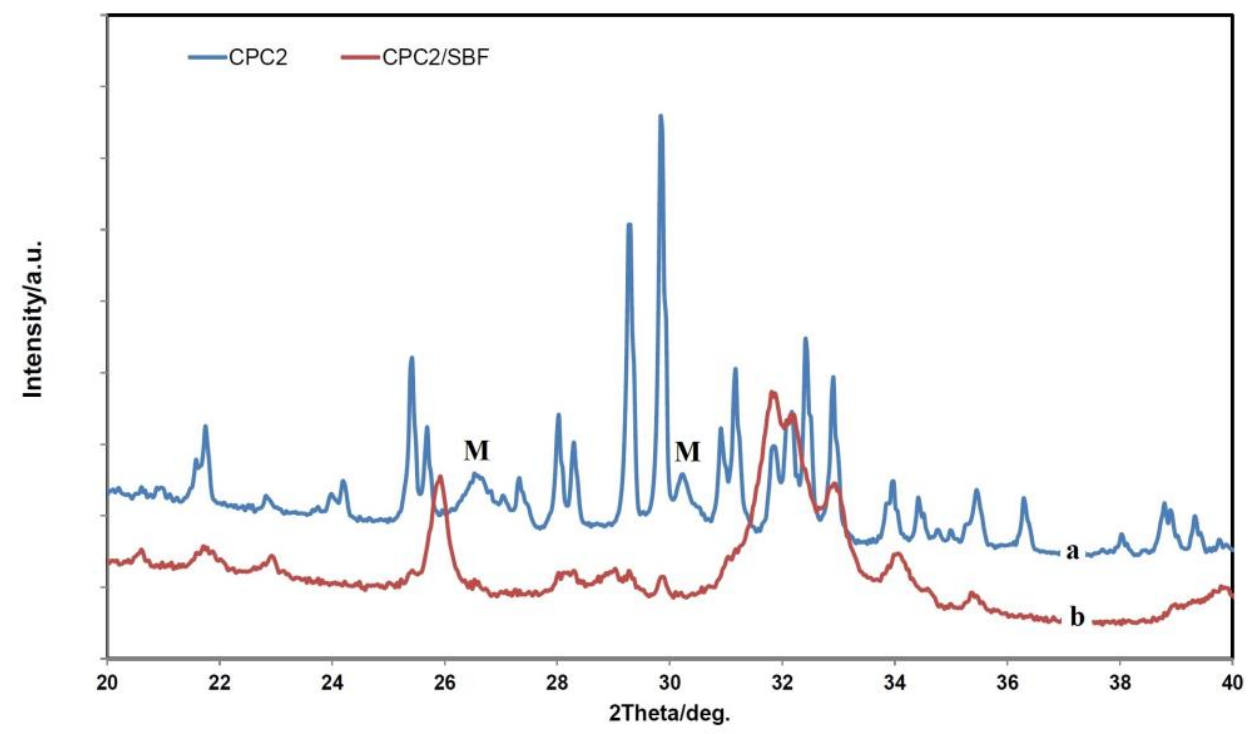

d)

Fig. 2. a) XRD patterns (H - hydroxyapatite, $\mathrm{S}-\mathrm{Si3N} 4, \mathrm{X}-\alpha \mathrm{TCP})$ and b,c) FTIR spectra of Simicro before (aa,ab,ac,ba (Simicro1), bb (Simicro3); ca (Simicro2)) and after (ad,ae,af; cb (Simicro2)) soaking in SBF at $37^{\circ} \mathrm{C}$; d) XRD patterns of $\mathrm{CPC} 2$, before (da) and after $(\mathrm{db})$ soaking in SBF at $37^{\circ} \mathrm{C}(\mathrm{M}$ - monetite $)$. 


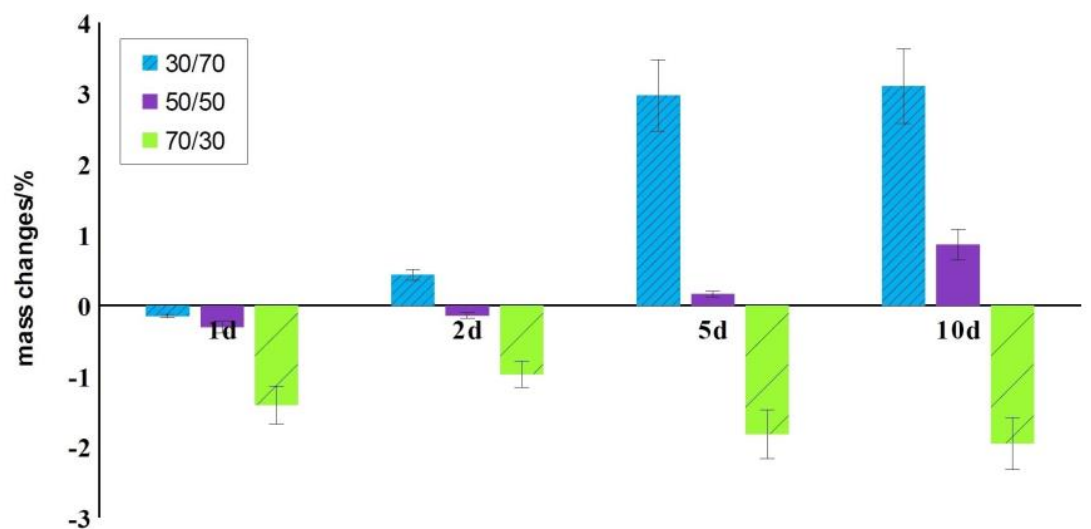

a)

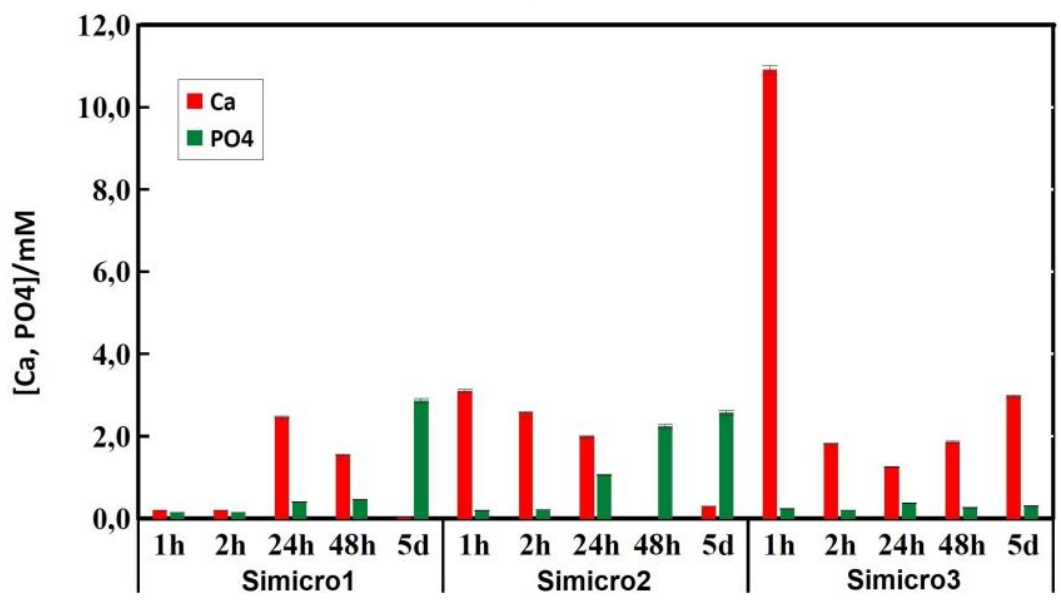

b)

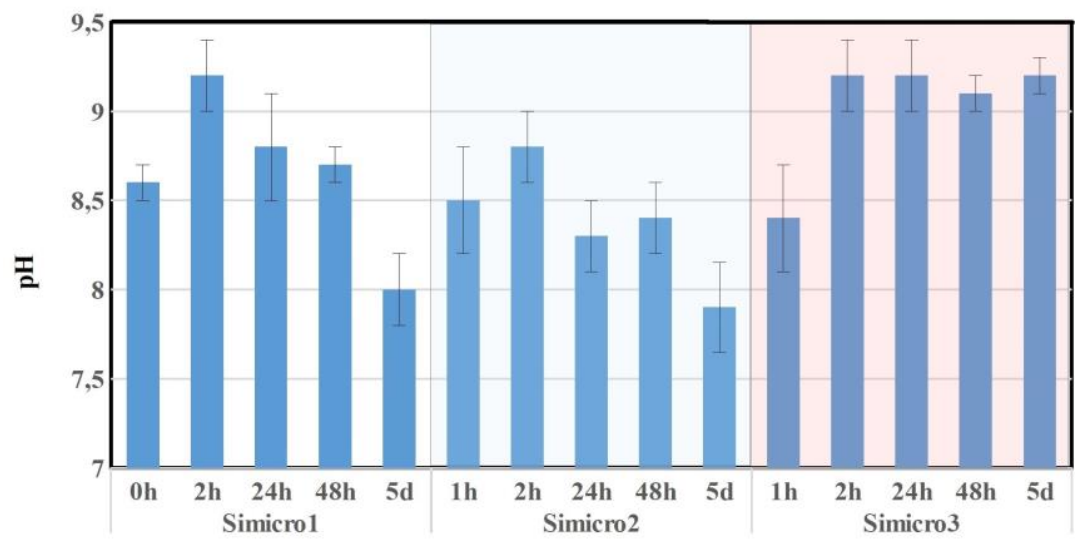

c)

Fig. 3. a) Mass changes, b) release of ions, and c) variations in $\mathrm{pH}$ during soaking of Simicro in $0.9 \% \mathrm{NaCl}$ solution at $37^{\circ} \mathrm{C}$. 
Mass changes of Simicro at various soaking times are shown in Fig. 3a. It is clear from the image that the mass increments rose with the content of $\alpha \mathrm{TCP}$ in Simicro - while the mass increment was about 3 wt. \% in Simicro 1, the mass losses of approx. 2 wt. \% were found in Simicro 3 after 10 days of soaking in SBF solution. Differences in the behavior of Simicro samples during soaking in $0.9 \% \mathrm{NaCl}$ solution demonstrate ion release in Fig. 3b. In the case of Simicro 1 and 2 with a higher portion of $\alpha \mathrm{TCP}$, dissolution of this phase was very slow at starting period in Simicro 1 because low concentrations of both $\mathrm{Ca}^{2+}$ and phosphate ions with the following rise after 24 hours of soaking were found in solution. On the other hand, up to 2-3 $\mathrm{mM}$ of calcium ions were released to a solution with a gradual decrease after 24 hours from Simicro 2. In both sample solutions, the amount of released phosphate ions rapidly rose after 48 hours whereas the concentration of calcium ions fell below the $0.1 \mathrm{mM}$ level. After 48 hours of soaking, the decrease in $\mathrm{pH}$ to $7.8-8$ was confirmed (Fig. 3c), which corresponds with an enhanced concentration of phosphate ions.

The concentration of calcium ions in Simicro 3 solution achieved minimum after 24 hours of soaking with a gradual rise to $2.5 \mathrm{mM}$ after 5 days. The amount of released phosphate ions (about $0.2 \mathrm{mM}$ ), as well as the $\mathrm{pH}$ (above 9), were almost the same during Simicro 3 soaking. For supplementing the above results, the morphology of particles in Simicro samples before and after 5 days of soaking in SBF was observed by SEM (Fig. 4). Very thin coating composed of extremely fine nanoparticles of newly formed phase was revealed on original particles of all Simicro and no other changes in particle morphology were found.

\section{Microstructure of composite cements}

The microstructure of CPC's 1-3 with 30 wt. \% addition of Simicro is shown in Fig. 5. In the microstructure of CPC1 (Fig. 5a), a small portion of larger irregularly shaped micropores of 10-20 $\mu \mathrm{m}$ size and a high number of micropores about 1-2 $\mu \mathrm{m}$ size is visible. Large spherical pinholes (40-60 $\mu \mathrm{m}$ in diameter) found in all CPC microstructures originate from the ripping of microgranules after the fracturing of samples. In Fig. 5c, the core of the microgranule ( $80 \mu \mathrm{m}$ size) only partially pulled out from the CPC3 cement matrix is clearly observed. In detailed images (e.g. Fig. 5d), the dense microstructure of the CPC1 matrix with a gradual rise in porosity with distance from the original microgranule's boundary was verified (arrow showed an increase in porosity). From the point of view of the morphology of HAP particles, formed at the boundaries between CPC matrix and the original particles of microgranules, after 7 days setting in SBF solution, the 200-500 nm size and rod-like morphology of HAP particles in CPC1 changed to the plate-like one with similar size in CPC2 and very fine rod-like (about $100 \mathrm{~nm}$ in size) in the case of CPC3. 


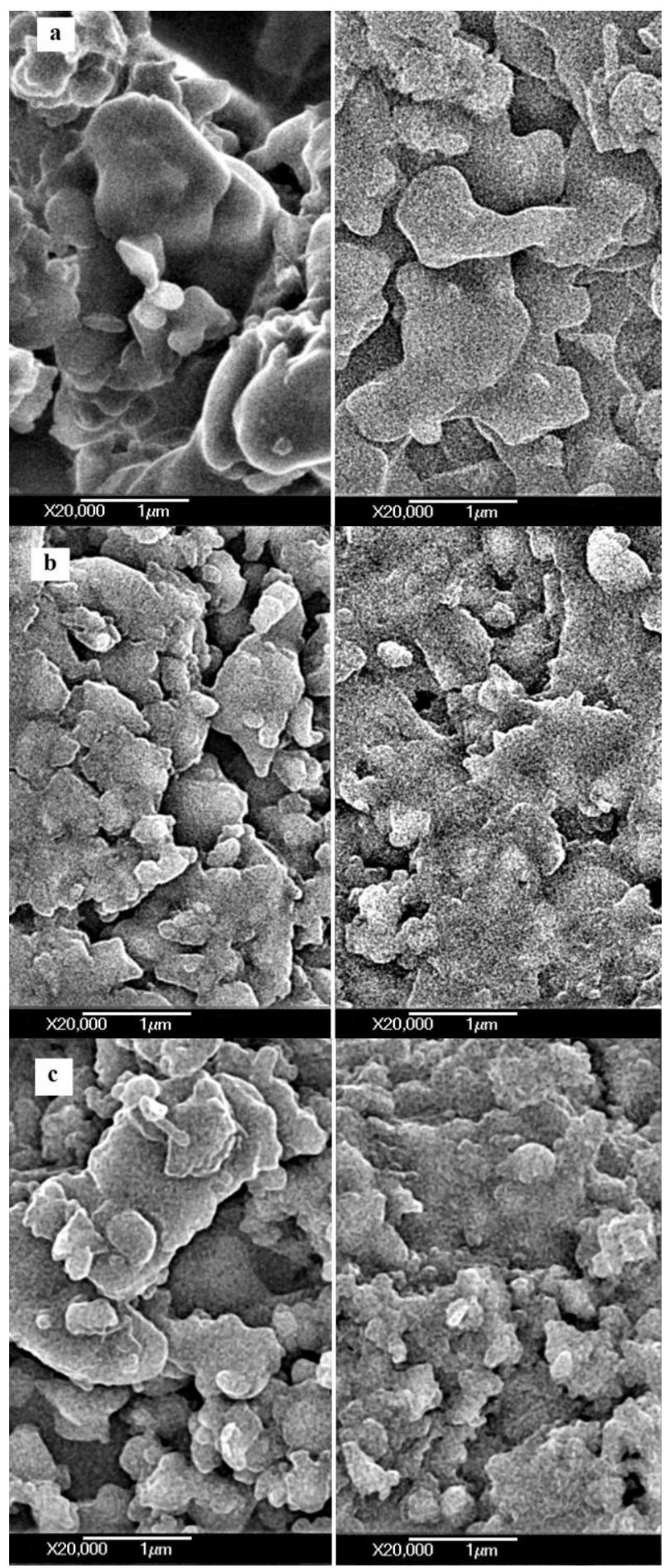

Fig. 4. Microstructure of Simicro before (left) and after (right) soaking in SBF for 5 days at $37^{\circ} \mathrm{C}$ : a) - Simcro1; b ) Simicro2; c) Simicro3. 

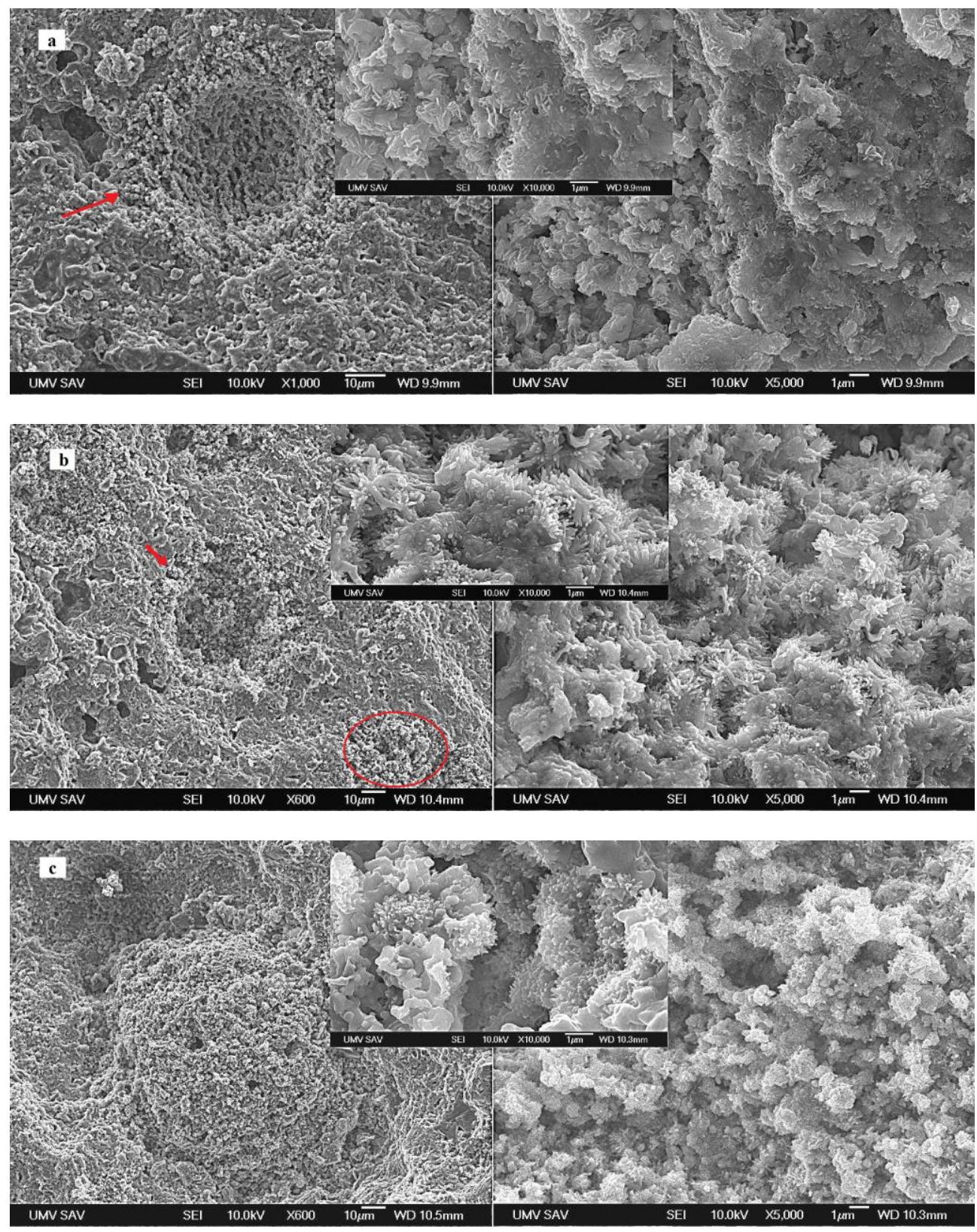


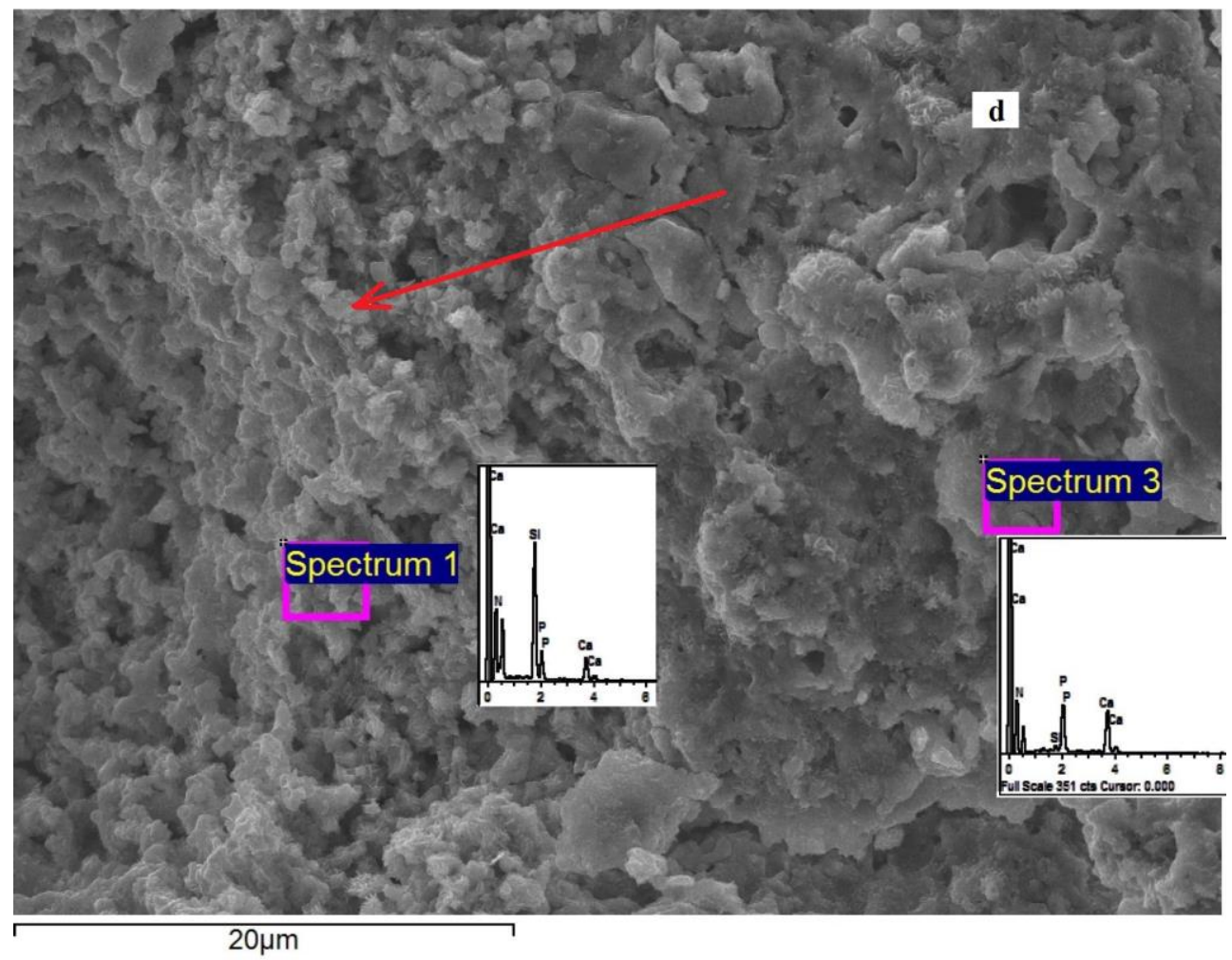

Fig. 5. Microstructure of CPC's 1-3 with 30 wt.\% addition of Simicro: a) CPC1 (arrow shows the location of microgranule); b) CPC2 (circle indicates the microgranule in the matrix); c) CPC3; d) CPC1 boundary between Simicro1 and cement matrix with EDX point analyses.

\section{Compressive strength and setting characteristics of CPC}

Wet and dry compressive strengths of CPC1-3 are compared in Tab. 1. Values of CS of all composite cements with 30 wt. \% addition of Simicro were much lower (about $30 \%)$ than of TTCPMH (CPC0) cement, but no significant differences $(\mathrm{p}<0.05)$ were measured between composite cements containing fine and middle fractions of Simicro. It was found that the decrease of Simicro content in CPC caused the rise in CS, which verified the negative influence of Simicro addition on the mechanical properties of composite cements. Similarly, despite the rise in dry CS of CPC's as compared with the wet ones, they were almost half of CS of CPC0. CS of cements in a dry state characterizes the strength of cement microstructure without side effects like capillary forces and viscosity of aqueous media in the filled micropores in the wet microstructure. In the case of setting time (ST), the ST rose with a decrease in $\alpha \mathrm{TCP}$ content in microgranules and the transformation rate of calcium phosphate phases in cements where ST of CPC3 was about $16 \pm 1$ min which was double of ST values for $\mathrm{CPC} 0$ and $\mathrm{CPC} 1$. 
Tab. 2. Compressive strength (CS) and setting time of composite cements

\begin{tabular}{|l|c|c|c|c|c|}
\hline \multirow{2}{*}{ Samples } & \multicolumn{3}{|c|}{ CS [MPa] } & \multicolumn{2}{c|}{ ST [min] } \\
\cline { 2 - 6 } & wet & dry & wet & $5 \pm 1$ & \\
\hline CPC0 & $24 \pm 3$ & $45 \pm 2$ & & 30 wt. \% Simicro & 10 wt. \% Simicro \\
\hline & \multicolumn{2}{|c|}{30 wt. \% Simicro } & 10 wt. \% Simicro & $7 \pm 1$ & $6 \pm 1$ \\
\hline CPC1 & $17 \pm 2$ & $33 \pm 2$ & $23 \pm 3$ & $11 \pm 2$ & $8 \pm 1$ \\
\hline CPC2 & $15 \pm 2$ & $26 \pm 3$ & $26 \pm 4$ & $16 \pm 1$ & $10 \pm 2$ \\
\hline CPC3 & $13 \pm 2$ & $24 \pm 2$ & $21 \pm 3$ & & \\
\hline
\end{tabular}

Note:

CPC 1 = TTCPMH + Simicro1; $\left(\right.$ Simicro1: volume ratios of $\left.\mathrm{Si}_{3} \mathrm{~N}_{4} / \mathrm{Ca}_{3}\left(\mathrm{PO}_{4}\right)_{2}-3 / 7\right)$

CPC 2 = TTCPMH + Simicro2; (Simicro2: volume ratios of $\left.\mathrm{Si}_{3} \mathrm{~N}_{4} / \mathrm{Ca}_{3}\left(\mathrm{PO}_{4}\right)_{2}-1 / 1\right)$

CPC 3 = TTCPMH + Simicro3; (Simicro3: volume ratios of $\left.\mathrm{Si}_{3} \mathrm{~N}_{4} / \mathrm{Ca}_{3}\left(\mathrm{PO}_{4}\right)_{2}-7 / 3\right)$

\section{Evaluation of in vitro cytotoxicity}

No cytotoxicity of Simicro extracts was verified and this fact confirmed that the concentration of released ions was less than cytotoxicity level (70\% of control) (Fig. 6a). On the other hand, a significantly lowered viability $(\mathrm{p}<0.001)$ of osteoblasts in contact with the composite cement surfaces was measured after 2 and 10 days of culture but the viability of cells cultured on CPC1 cement exceeds cytotoxicity $(\mathrm{p}<0.05)$ level characterized by 70 $\%$ of negative control viability (Fig. 6b).

\section{Release of dexamethasone from CPC}

In Fig. 7, the release of dexamethasone from CPCO (TTCPMH powder mixture) and CPC2 composite cements are compared. A burst effect was measured during the first $2 \mathrm{~h}$ of dex release, characterized by a rapid rise of concentration up to $\sim 0.05 \mu \mathrm{g} / \mathrm{ml}$, what equals $15 \%$ and $35 \%$ of total amount of dex, added to the TTCPMH and CPC 2 mixtures respectively.

A large difference in the cumulative relative amount of dex released from these cements is caused by the higher content of dex in TTCPMH due to the fact that CPC2 contained only $30 \mathrm{wt}$. $\%$ of Simicro2dex with the same content as in TTCPMHdex. It should be noted that almost the full amount of dex (about 97\%) was released from Simicro2 during the first $2 \mathrm{~h}$ of release in the separated experiment, from which is evident insignificant drug adsorption on the surface or pores of microgranules. 

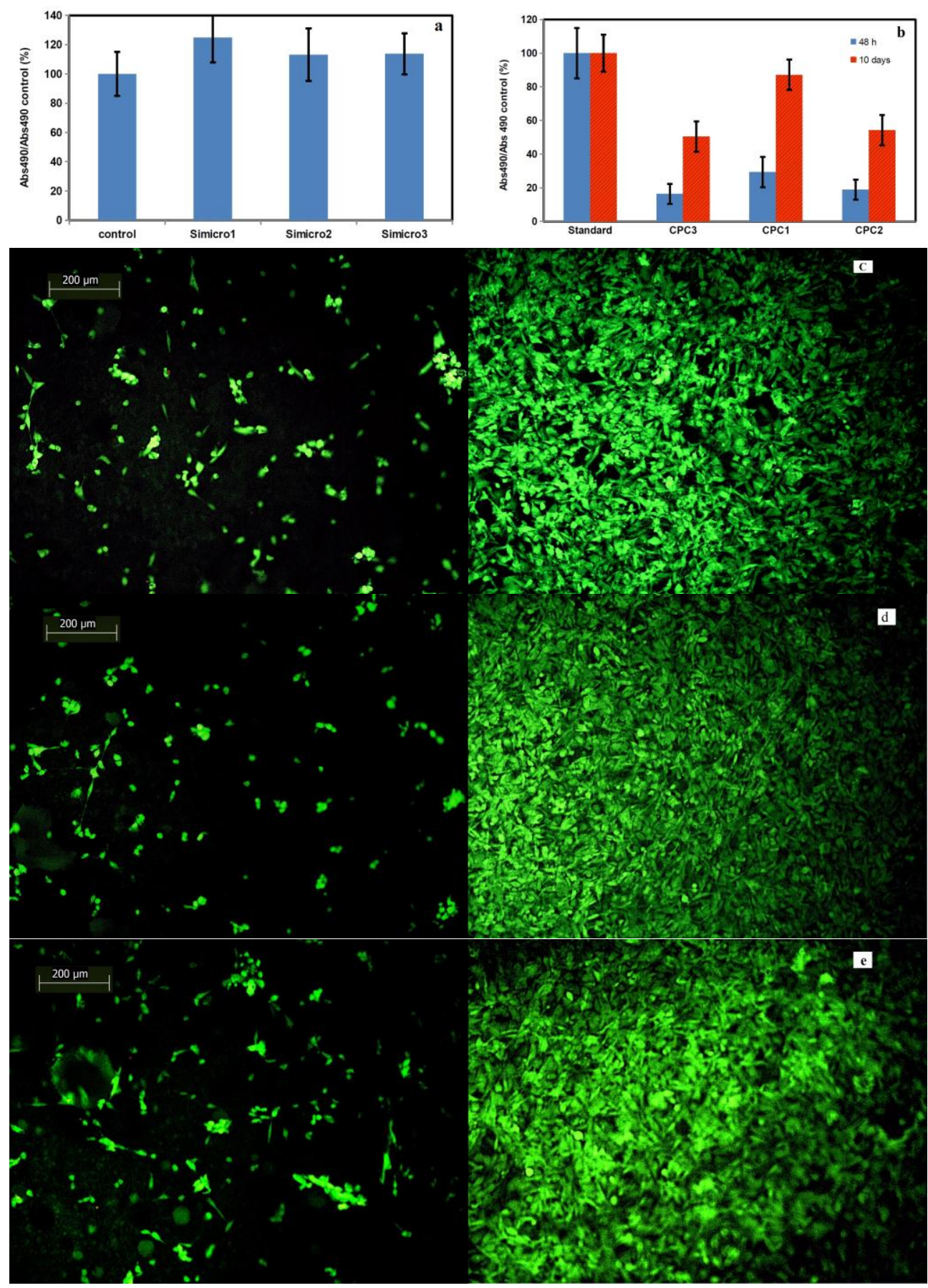

Fig. 6. a) Viability of cells cultured in $100 \%$ extracts for $24 \mathrm{~h}$ and b) on CPC1-3 for $48 \mathrm{~h}$ and 10 days at $37{ }^{\circ} \mathrm{C}, 5 \% \mathrm{CO}_{2}$ and $96 \%$ humidity; live/dead staining cells cultured on c) CPC1; d) CPC2 and e) CPC3 for 48 h (left) and 10 days (right). 


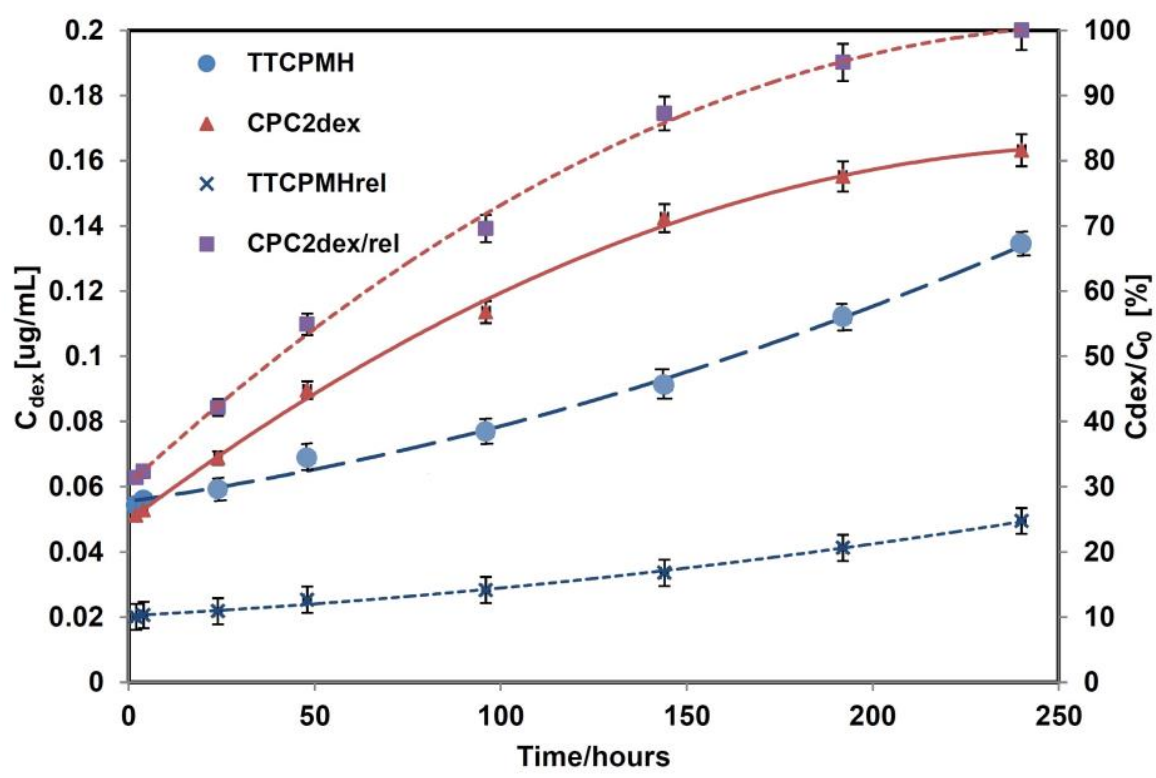

Fig. 7. Release of dexamethasone from TTCPMH and CPC2 cements.

\section{DISCUSSION}

Based on preliminary experiments focused on the optimization of mechanical properties and microstructure of composite cements resulted in an insignificant difference between fine and middle fractions Simicro but it was hard to achieve good homogeneity and distribution of coarser Simicro in CPC. Besides the fine Simicro fractions contained a larger amount of irregularly shaped particles with size $<10 \mu \mathrm{m}$, which were not appropriate in an application for controlled drug release (especially with slower release rate) due to the lower inner volume of the open pores (smaller amount of drug can be introduced to pores of microgranules) and higher releasing rate (shorter distances between surface and core of microgranules as well as a large surface area). For these reasons, CPC composite cements with the addition of the middle fraction of Simicro were characterized only. Open porosity of Simicro 1, 2, and 3 measured by He pycnometer was close to $80 \mathrm{vol}$. \% but a higher density of samples with enhanced $\alpha \mathrm{TCP}$ content was found which corresponds with a strengthened microstructure of microgranules.

The coarser particles were clearly visible on Simicro1 and 2 (with a higher fraction of $\alpha \mathrm{TCP}$ ) after soaking in SBF which can indicate a thicker calcium phosphate layer on the particles. Notably, all coarser microgranules were disintegrated to particle agglomerates with the size of $<10 \mu \mathrm{m}$ even after 1 day of soaking in SBF, which demonstrates both the weak mechanical strength of microgranules, so as a partial dissolution of $\alpha \mathrm{TCP}$ phase which were strengthening their original microstructure. Thus, soaking in SBF solution revealed relatively low bioactivity of microgranules to the formation of calcium phosphate coating on Simicro 2 and 3 which is in accordance with XRD and FTIR analyses. In the case of composite cements, the XRD analysis (Fig. 2d) showed that the final product of the cement transformation was nanocrystalline calcium deficient HA (PDF4 01-071-5048).

Notable, that the microstructure and the shape of microgranules were not damaged during the preparation of cements, which had a key role in the total porosity of CPC composites and utilization for the change of drug release rate. Microgranules were tightly 
interconnected with the surrounding CPC matrix via HAP particles formed at the boundaries of the original Simicro particles. In all SEM images of cements shells or surface layers from the original microgranules with a thickness of about $10 \mu \mathrm{m}$ can be found. They were not able to detach from the matrix due to the sufficient bonding, contrary to the core of microgranules in deeper regions (at the far distance from the calcium phosphate matrix). From the above-described facts results that the Simicro cores were not able to strengthen the CPC because the maximum concentration of calcium and phosphate ions was reached in close contact with cement matrix during the transformation of starting calcium phosphates in cements.

In all cements, HAP nanoparticles form islands or globular agglomerates growing on original particles of microgranules (especially fine in CPC3) or were present in the form of more compact agglomerates in the cement matrix. The comparison showed the dependence of HAP particle dimensions at Simicro boundaries on the amount of $\alpha \mathrm{TCP}$ in microgranules.

The highest value of CS had CPC1 with Simicro 1, containing the largest amount of $\alpha \mathrm{TCP}$. From the comparison of CS of CPC0 and composite cements, concerning a microstructure, it is clear, that the reduced strength of microgranules was responsible for the decrease in CS of final composite cements, despite the good interconnection between the boundaries of microgranules and a stronger cement matrix. It should be noted, that the density of composite cements was about $20 \%$ lower after the addition of Simicro due to the higher porosity of microgranules (CPC0 had about $43 \%$ porosity contrary to $59 \%$ porosities of CPC1-3). The compact whisker-reinforced CPC, with a 5 wt. \% addition of SrHA revealed the highest compressive strength of $2.92 \mathrm{MPa}$, which was almost 2-times higher than that of the pure CPC [26]. The addition of SiC/nanosilica whiskers to CPC filler applied in Bis-GMA-based resins caused the rise in flexural strength from $50 \mathrm{MPa}$ to 160 MPa [24]. Because of the complications with the analysis of correct mechanical strength of Simicro, for a better understanding of the measured strengths, it should be mentioned CS of $\mathrm{Si}_{3} \mathrm{~N}_{4}$ porous ceramics with close porosity as was measured here for Simicro. For example, ceramics with about $70 \%$ porosity had CS less than $8 \mathrm{MPa}$ [34] or in the case of silicon nitride prepared using 3D printing - only about $5 \mathrm{MPa}$ [35]. Naturally, there are differences in composition and the pore size distribution as compared with our CPC composites, but values lower than $10 \mathrm{MPa}$ of CS were registered.

Contrary to the previous preparation procedure, where microgranules with similar composition were synthesized using the flame synthesis and relatively severe in vitro cytotoxicity of extracts was observed [36], analysis of cytotoxicity of Simicro extracts showed the acceptable composition of Simicro prepared by the presented method.

In the case of contact cytotoxicity of cements, despite the rise in the viability of osteoblasts (more than fivefold) with cultivation time on composite cements CPC 2 and 3, both samples were potentially cytotoxic after 10 days culture. We assume that the reason for the lower viability for cements was the surface cement texture which strongly affects the cell adhesion. Live/dead staining of osteoblasts (Fig. 6 c,d,e) demonstrated a low number of adhered live cells after 48 hours of cultivation with the rapid population growth after 10 days of culture which was in accordance with the results of the MTS proliferation test.

Compared to TTCPMHdex (0.3 ng dex per hour), the faster release of dex was revealed for CPC2dex (0.7 ng dex per hour) and the full amount of dex was released from CPC2dex after 10 days of soaking. In the case of TTCPMHdex, the slow gradual increase of dex concentration with releasing time was observed and the amount of dex released, after 10 days of soaking, reached about $25 \%$ of total dex content. The above-described facts 
demonstrated that the addition of Simicrodex to TTCPMH significantly accelerated the release rate of dex due to the lower density of composite cement with a more opened microstructure. For a description of release kinetics, data were fitted by the various models. From detailed analysis, based on the comparison of correlation coefficients, resulted that the dexamethasone release kinetics from CPC2dex was well characterized by the Higuchi's equation $\left(\mathrm{R}^{2}=0.994\right.$ contrary to 0.942 of TTCPMHdex) which is an appropriate model for the description of the release of drug particles in the uniform matrix or diffusion-controlled release of low soluble drugs from the solid matrix. In the case of TTCPMHdex cement, kinetics meet the equation for the first-order kinetics $\left(R^{2}=0.998\right.$ in comparison with 0.947 for CPC2dex) which characterize the behavior of water-soluble drugs in the porous matrix [37]. In the case of CPC2dex, dexamethasone was initially absorbed in Simicro micropores where could be dissolved higher amount of drug with the following transfer by diffusion over more opened microstructure containing the enhanced volume of the aqueous medium. On the other hand, a much lower amount of dexamethasone was released from TTCPMHdex because of the higher cement density and smaller volume of aqueous media, despite summary higher content of dexamethasone in the cement matrix. Note that the release rate of dex can be affected by a combination of Simicrodex with TTCPMHdex or by the change of dexamethasone content in microgranules. The cumulative release rate of TTCPMHdex was comparable with the one from dex-loaded porous calcium phosphate cements where dex was added to hardening liquid [38]. The release kinetics of drugs from porous hydroxyapatite cement matrix is usually diffusion-controlled because of the resorption ability and the solubility of hydroxyapatite, which is much lower than the diffusion rate of drugs [39].

\section{CONCLUSIONS}

The Simicro showed good SBF in vitro bioactivity characterized by the formation of calcium phosphate coating with increasing content of $\alpha \mathrm{TCP}$ in microgranules. The addition of Simicrodex to TTCPMH accelerated the release rate of dexamethasone from CPC due to lower density with more opened cement microstructure which resulted in the effective action of microgranules on control of drug release. Mechanical properties of $\mathrm{CPC} 0$ cement were reduced after the addition of Simicro contrary to their improvement with the amount of $\alpha \mathrm{TCP}$ in Simicro but more strengthen microgranules should be prepared for cement strengthening. The final phase after CPC setting was calcium deficient hydroxyapatite and setting time decreased with the content of $\alpha$ TCP in Simicro. Simicro was sufficiently interconnected with calcium phosphate cement matrix via precipitated hydroxyapatite at boundaries but the compressive strength of CPC composites was strongly influenced by the weak strength of the highly porous microstructure of microgranules. No cytotoxicity of Simicro extracts was found contrary to revealed enhanced contact cytotoxicity of CPC's containing Simicro with lowered content of $\alpha \mathrm{TCP}$.

\section{ACKNOWLEDGEMENTS}

This work was supported by the Slovak Grant Agency of the Ministry of Education of the Slovak Republic and the Slovak Academy of Sciences, Project APVV-170110, VEGA 2/0069/20, and Project No. 2/0152/18.

\section{REFERENCES}

[1] Constantz, BR., Barr, BM., Ison, IC., Fulmer, MT., Baker, J., McKinney, L., Goodman, SB., Gunasekaren, S., Delaney, DC., Ross, J., Poser, RD.: J. Biomed. Mater. Res. Appl. 
Biomater., vol.43, 1998, p. 451.

[2] Ginebra, MP., Fernandez, E., De Maeyer, EAP., Verbeeck, R.M.H., Boltong, M.G., Ginebra, J., Driessens, FCM., Planell, JA.: J. Dent. Res., vol. 76, 1997, p. 905.

[3] Miyamoto, Y., Ishikawa, K., Fukao, K., Sawada, M., Nagayama, M., Kon, M., Asaoka, K.: Biomaterials, vol. 16, 1995, p. 855.

[4] Costantino, PD., Friedman, CD.: Otolaryngol. Clin. North. Am., vol. 27, 1994, p. 1037.

[5] Friedman, CD., Costantino, PD., Takahi, S., Chow, LC.: J. Biomed. Mater. Res. Appl. Biomater., vol. 43, 1998, p. 428.

[6] Shindo, ML., Constantino, PD., Friedman, CD., Chow, LC.: Arch. Otolaryngol. Head Neck Surg., vol. 119, 1993, p. 185.

[7] Sugawara, A., Chow, LC., Takagi, S., Chohayeb, H.: J. Endodon., vol. 16, 1990, p. 162.

[8] Tenhuisen, KS., Brown, PW.: J. Biomed. Mater. Res., vol. 36, 1997, p. 233.

[9] Liu, CS., Shao, HF., Chen, FY., Zheng, HY.: Biomaterials, vol.24, 2003, p. 4103.

[10] Ishikawa, K., Eanes, ED.: J. Dent. Res., vol. 72(2), 1993, p. 474.

[11] Yang, Q., Troczynski, T., Liu, DM.: Biomaterials, vol. 23, 2002, p. 2751.

[12] Takahashi, K., Fujishiro, Y., Yin, S., Sato, T.: Ceram. Int., vol. 30, 2004, p. 199.

[13] Evis, Z., Doremus, RH.: Mat. Sci. Eng. C, vol. 27, 2007, p. 421.

[14] Juang, HY., Hon, MH.: Mat. Sci. Eng. C, vol. 2, 1994, p. 77.

[15] Kong, YM., Bae, CHJ., Lee, SH., Kim, HW., Kim, HE.: Biomaterials, vol. 26, 2005, p. 509.

[16] Bal, BS., Rahaman, MN.: Acta Biomater., vol. 8, 2012, p. 2889.

[17] Neumann, A., Kramps, M., Ragoß, C., Maier, HR., Jahnke, K.: Materialwiss. Werkst., vol. 35, 2004, p. 569.

[18] Dusza, J., Šajgalík, P.: N.P. Cheremisinoff, PN. Cheremisinoff (Eds.), Handbook of Advanced Materials Testing, Marcel Dekker Inc., New York, 1995, p. 399.

[19] Mazzocchi, M., Bellosi, A.: J. Mater. Sci: Mater. Med., vol. 19, 2008, p. 2881.

[20] Mazzocchi, M., Gardini, D., Traverso, PL., Faga, MG., Bellosi A.: J. Mater. Sci: Mater. Med., vol.19, 2008, p. 2889.

[21] Neumann, A., Reske, T., Held, M., Jahnke, K., Ragoß, C., Maier, HR.: J. Mater. Sci: Mater. Med., vol. 15, 2004, p. 1135.

[22] Anderson, MC., Olsen, R.: J. Biomed. Mater. Res., vol. 92A, 2010, p.1598.

[23] Guedes e Silva, CCH., da Silva Rigob, EC., Marchic, J., de Almeida Bressianic, AH., Bressiani, JC.: Mater. Res., vol. 11, 2008, p. 47.

[24] Xu, HHK., Smith, DT., Simon, CG.: Biomaterials, vol. 25, 2004, p. 4615.

[25] Xu, HHK., Quinn, JB.: J. Biomed. Mater. Res., vol. 57, 2001, p. 165.

[26] Shen, Y., Liu, J., Lin, K., Zhang, W.: Mater. Lett., vol. 70, 2012, p. 76.

[27] Kruger, R., Seitz, JM., Ewald, A., Bach, FW., Groll, J.: J. Mech. Behav. Biomed. Mater., vol. 20, 2013, p. 36.

[28] Mourino, V., Boccaccini, AR.: J. R. Soc. Interface, vol. 7, 2010, p. 209.

[29] Oshina, H., Sotome, S., Yoshii, T., Torigoe, I., Sugata, Y., Maehara, H., Marukawa, E., Omura, K., Shinomiya, K.: Bone, vol. 41, 2007, p. 575.

[30] Zor, T., Selinger, Z.: Anal. Biochem., vol. 236, 1996, p. 302.

[31] Wada, N., Solin, SA., Wong, J., Prochazka, S.: J. Non-Cryst. Solids, vol. 43, 1981, p. 7.

[32] Kolmasa, J., Kaflaka, A., Zima, A., Ślósarczyk, A.: Ceram. Int., vol. 41, 2015, p. 5727.

[33] Carrodeguas, RG., De Aza, S.: Acta Biomater., vol. 7, 2011, p. 3536.

[34] Bodišová, K., Kašiarová, M., Domanická, M., Hnatko, M., Lenčéš, Z., Varchulová Nováková, Z., Vojtaššák, J., Gromošová, S., Šajgalík, P.: Ceram. Int., vol. 39, 2013, p. 
8355.

[35] Ma, L., Song, Y., Li, X., Li, R., Shang, Z., Wang, Y.: Ceram. Int., vol. 44, 2018, p. 11730.

[36] Fenclová, T., Jonšta, Z., Hnatko, M., Kraxner, J., Šajgalík, P.: Resolution and Discovery, 2018, p.16.

[37] Costa, P., Lobo, JMS.: Eur. J. Pharm. Sci., vol. 13, 2001, p. 123.

[38] Forouzandeh, A., Hesarakin, S., Zamanian, A.: Ceram. Int., vol. 40, 2014, p. 1081.

[39] Ginebra, MP.,Traykova, T., Planell, JA.: J. Control. Rel., vol. 113, 2006, p. 102. 